\title{
Liquid Crystal Thermography in Gas Turbine Heat Transfer: A Review on Measurement Techniques and Recent Investigations
}

\author{
Srinath V. Ekkad ${ }^{1}$ and Prashant Singh ${ }^{2, *}$ \\ 1 Mechanical and Aerospace Engineering Department, North Carolina State University, Raleigh, NC 27695, \\ USA; sekkad@ncsu.edu \\ 2 Mechanical Engineering Department, Mississippi State University, Mississippi State, MS 39762, USA \\ * Correspondence: singh@me.msstate.edu
}

check for updates

Citation: Ekkad, S.V.; Singh, P. Liquid Crystal Thermography in Gas Turbine Heat Transfer: A Review on Measurement Techniques and Recent Investigations. Crystals 2021, 11, 1332 https://doi.org/10.3390/ cryst11111332

Academic Editor: Shin-Tson Wu

Received: 9 October 2021

Accepted: 28 October 2021

Published: 31 October 2021

Publisher's Note: MDPI stays neutral with regard to jurisdictional claims in published maps and institutional affiliations.

Copyright: (c) 2021 by the authors. Licensee MDPI, Basel, Switzerland. This article is an open access article distributed under the terms and conditions of the Creative Commons Attribution (CC BY) license (https:// creativecommons.org/licenses/by/ $4.0 /)$.

\begin{abstract}
Liquid Crystal Thermography is a widely used experimental technique in the gas turbine heat transfer community. In turbine heat transfer, determination of the convective heat transfer coefficient $(h)$ and adiabatic film cooling effectiveness $(\eta)$ is imperative in order to design hot gas path components that can meet the modern-day engine performance and emission goals. LCT provides valuable information on the local surface temperature, which is used in different experimental methods to arrive at the local $h$ and $\eta$. The detailed nature of $h$ and $\eta$ through LCT sets it apart from conventional thermocouple-based measurements and provides valuable insights into cooling designers for concept development and its further iterations. This article presents a comprehensive review of the state-of-the-art experimental methods employing LCT, where a critical analysis is presented for each, as well as some recent investigations (2016-present) where LCT was used. The goal of this article is to familiarize researchers with the evolving nature of LCT given the advancements in instrumentation and computing capabilities, and its relevance in turbine heat transfer problems in current times.
\end{abstract}

Keywords: liquid crystal thermography; LCT; turbine heat transfer

\section{Introduction}

Gas turbine blade cooling innovation is driven by the constant push for higher turbine inlet temperatures for higher overall gas turbine efficiency and reduced coolant usage, for overall efficient fuel management, with a broader goal to achieve lower emissions [1]. Both propulsion and power generation industry-based gas turbine engines are poised to play a vital role in determining the global carbon footprint. To this end, several innovative cooling technologies have been developed and adopted in present-day turbines and these concepts are also used widely in other areas involving the need for high heat dissipation rates. A comprehensive review of gas turbine cooling technologies, up until 2010, is presented by Han et al. [2]. The foundation of any enhanced heat transfer concept development effort is the accurate measurement of the involved thermal quantities that determine the heat transfer quantities of interest, which in the case of gas turbine cooling is $h$ and $\eta$. Over the years, significant efforts have been dedicated to developing stable and robust measurement techniques that can accurately quantify the local cooling characteristics of typical concepts such as rib turbulators, jet impingement, pin fins and film cooling. Of these, experimental techniques that yield a detailed map of the heat transfer coefficient $(h)$ and adiabatic film cooling effectiveness $(\eta)$ are of prime importance as they show the local effects and provide valuable insights into the design modifications, rather than one global value. Liquid crystal and infrared thermography methods are common in the gas turbine heat transfer community, where both methods have been explored in extensive detail over the past three decades or so, where liquid crystal thermography has been in existence since the early 1980s. Earlier work by Jones and Ireland [3] from the University of Oxford was amongst the first to showcase liquid crystals and their usage in gas turbine heat transfer 
applications. Since then, prominent research groups at Oxford, University of Minnesota [4], UC Davis [5], Arizona State University [6], Texas A\&M [7], Penn State [8], Northeastern [9] and many more have successfully used this technique in many heat transfer scenarios.

With the advancements in measurement devices and computing capabilities, the techniques have evolved over the years, which, in turn, has affected the quality of the reported heat transfer quantities. To this end, this paper reviewed some conventional measurement techniques involving liquid crystal thermography as well as some recently developed ones. Furthermore, representative experimental studies were reviewed, with a focus on studies done in the past five years (2016-present).

\section{Fundamentals of Liquid Crystal Thermography (LCT)}

\subsection{Working Principle}

Liquid crystals have unique properties, which lie in between that of a typical crystalline solid and isotropic liquids. Their relative placements are shown as shown in Figure 1, along with the role of temperature in the rods' orientation. This process is reversible as well, which makes LCs reusable. Figure 1 also shows the three mesophases in which liquid crystals can exist, viz. (a) nematic, (b) smectic, and (c) cholesteric. In the nematic phase, the molecules are arranged in a more symmetrical way about the vertical axes and are called "achiral". In the smectic phase, the layers can move relative to each other, exhibiting properties of typical liquids. In the cholesteric mesophase, the elongated molecules are not symmetrical with respect to the vertical axes, or they are twisted in reference to the axes, which results in the intramolecular forces rotating each molecule relative to one another. This essentially results in LCs taking the form of a helix with a certain pitch. For cholesteric liquid crystals involved in temperature measurements, this pitch should be of the same order as that of the wavelength of the excitation light it is subjected to.

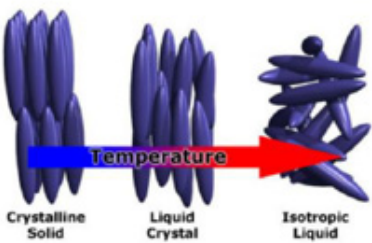

LC in reference to solid and liquid

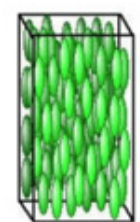

(a)

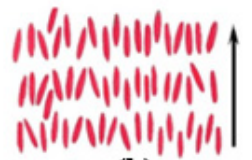

(b)

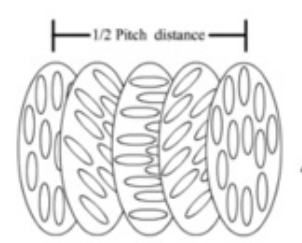

(c)

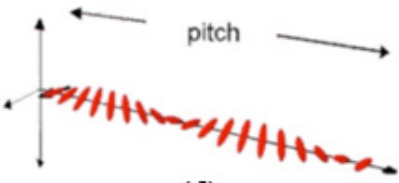

(d)

Liquid crystal mesophases: (a) Nematic, (b) Smectic, (c,d ) Cholesteric

Figure 1. Liquid crystals in reference to crystalline solid and isotropic liquids (left), and the different mesophases of liquid crystals, (a) nematic, (b) smectic, (c) cholesteric, (d) cholesteric (different view) [10]. Figure from an open-access article.

When the LCs are exposed to light of a certain wavelength, due to constructive interference, there is a selective reflection of light whose wavelength is given by Bragg's law, $\lambda=n p \sin \theta$, where $n$ is the refractive index of LCs, $0.5 p$ is the spacing between similar planes in the material, and $\theta$ is the incidence angle of the light. The LCs that are employed in temperature measurement problems are encapsulated within thin gelatin walls, where the capsules are typically 20 microns in size. This binding of LCs is required to prevent its degradation from chemical or mechanical influences. The above properties of liquid crystals when they are subjected to a certain temperature and exposed to light of a suitable wavelength as well as their reusability and effective packaging (encapsulation) make them a promising candidate for thermometry.

\subsection{Color to Temperature Conversion or Color Perception}

The LC color change is recorded by a standard CCD camera and this recording is later post-processed to convert the colors into a known wall temperature. However, the first step in this process is color perception. In the RGB color space, any color can be obtained by linear combinations of red, green and blue color contents. With the knowledge of the $\mathrm{R}$, $\mathrm{G}$ and $\mathrm{B}$ color contents of each pixel, one can obtain their temporal evolution which can be 
correlated to an in situ wall temperature measurement. Typically, the red and green color intensities are used to either correlate the start of the red and green colors or peak red or green colors with the wall temperature [11]. Another method of color perception is to observe this phenomenon in the Hue, Saturation and Intensity (HSI) space. In the HSI space, the individual values of $H, S$ and I can be obtained with the knowledge of the R, G and B color contents of a given pixel. Typically, Hue is correlated to wall temperature [12]. There are, however, different equations used in the past for obtaining Hue, e.g., Hay and Hollingsworth [13] used $H=\tan ^{-1}(\sqrt{3}(R-G) /(2 R-G-B))$, whereas Hacker and Eaton (cited by [14]) proposed using $H=(255 / \pi) \tan ^{-1}(0.5(R-G) /(0.25(R-G)+0.5 B))$. Recent practice is to use software such as MATLAB and use its inbuilt RGB2HSV command to convert R, $\mathrm{G}$ and $\mathrm{B}$ signals into H, S and V. Here, V is the same as I. More details on the LC color perception, calibration and issues can be found in $[15,16]$.

\section{Experimental Methods in Heat Transfer Measurements}

Liquid crystal thermography is employed under both steady-state and transient heat transfer experiments in order to find the local heat transfer coefficient and/or film cooling effectiveness through finding the local wall temperature from the color change of liquid crystals at certain color play bands. Liquid crystal thermography has now evolved into a robust technique over the years, which is very popular in the turbine cooling community due to its ease of application on a surface and simple conversion to a local wall temperature. Thermochromic liquid crystals in a micro-encapsulated form are sprayed on a surface, where these spherical particles $(\sim 20 \mu \mathrm{m})$ are glued together via a suitable adhesive (also called "binders"). These chiral nematic structures when exposed to light of a suitable wavelength at a certain crystal temperature reflects light at a certain wavelength governed by Bragg's reflection formula $(\lambda=n p \sin \theta)$. The reflected light from the surface is captured by a regular charged coupled device (CCD) camera. The liquid crystal color change images captured by the CCD camera is interpreted in different ways through image processing tools to establish a relationship between an incident in the color change process to a surface temperature. More details on liquid crystal thermography can be found in Ireland and Jones [17], and its applications in Ekkad and Han [18]. Different methods for color change to wall temperature conversion are presented in Camci et al. [8] and Hay and Hollingsworth [13]. The following is a brief discussion on the design of an experimental setup for LCT under different types of conditions.

\subsection{Heat Transfer Measurement Techniques}

\subsubsection{Steady-State Heat Transfer Experiments}

The assembly for steady-state LC-based experiments is shown in Figure 2, which includes Styrofoam, gold film (electrically heated), plexiglass plate, black paint and a liquid crystal. The assembly ensures a uniform heat flux $\left(q^{\prime \prime}\right)$ distribution over the twodimensional target surface subjected to an incoming impinging jet, and $q^{\prime \prime}$ is calculated by measuring the voltage drop $(V)$ across the electric heater $\left(q=V^{2} / R\right)$ of the net electrical resistance $(R)$. The convective heat transfer coefficient $(h)$ is defined as $h=q^{\prime \prime} /\left(T_{w}-T_{f}\right)$, where in this case the wall temperature is determined from image processing of the liquid crystal color change and the fluid temperature is measured by thermocouples. 


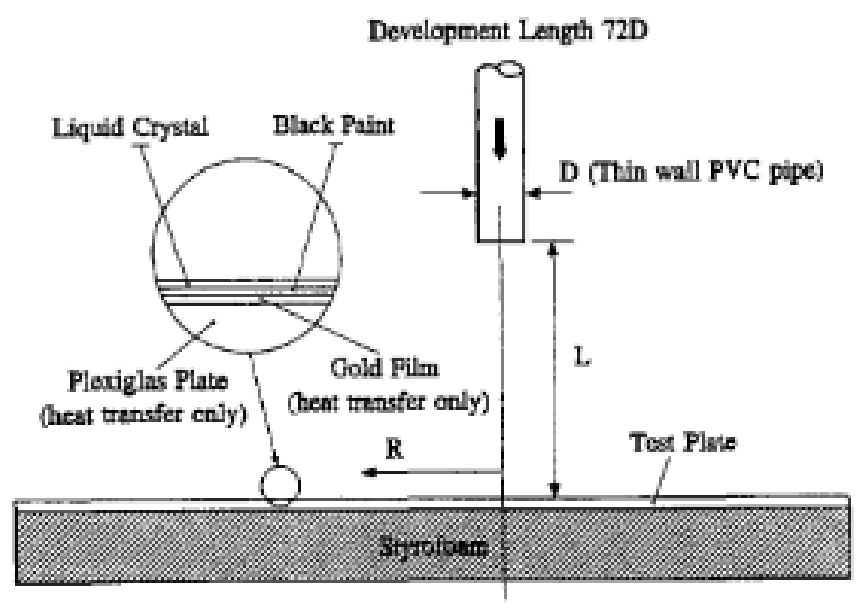

Figure 2. Liquid crystal-based experimental setup [5]. Reprinted with permission: License number 5177100108751.

\subsubsection{Transient Heat Transfer Experiments: Solid Modeled as Lumped Capacitance}

The lumped capacitance model used above under steady-state conditions is also extended to transient conditions when a sudden change in fluid or solid temperature is induced and the resultant wall temperature evolution is measured. One such method was originally proposed by Abuaf et al. [19] in a linear cascade for measuring the convective heat transfer coefficient and adiabatic film cooling effectiveness on the surface of an airfoil place inside the cascade. The transient lumped capacitance model-based technique works on the assumption that the energy transfer from the fluid to the solid is completely utilized in increasing the solid's internal energy. The Biot number analysis $(\mathrm{Bi}<<1)$ used above needs to hold true for this case as well. The convective heat transfer coefficient is then defined as

$$
h=-\left(\rho l c_{p} / t\right) \ln \left(\left(T_{\text {jet }}-T_{\text {plate }}(t)\right) / T_{\text {jet }}-T_{i}\right)
$$

where $\rho$ is the plate density, $c_{p}$ is the specific heat capacity, $l$ is the plate thickness and $T_{\text {plate }}$ is measured by Liquid Crystal Thermography (LCT). The authors in [19] also extended this technique to study the surface roughness effects on the heat transfer of turbine airfoils in [20].

\subsubsection{Transient Heat Transfer: Solid Modeled as One-Dimensional Semi-Infinite}

The most popular technique based on TLC is the one where a solid can be treated as semi-infinite during short-duration transient experiments. These solids are typically made of clear acrylic with a thermal conductivity $\left(k_{s}\right)$ of $\sim 0.2 \mathrm{~W} / \mathrm{mK}$ and thermal diffusivity $(\alpha)$ of $\sim 1.1 \times 10^{-7} \mathrm{~m}^{2} / \mathrm{s}$. The wall temperature $\left(T_{w}\right)$ evolution with time for a solid initially at $T_{i}$ subjected to sudden change in ambient fluid temperature $\left(T_{m}\right)$ is given as

$$
T_{w}(t)=T_{i}+\left(T_{m}-T_{i}\right)\left(1-\exp \left(\beta^{2}\right) \operatorname{erfc}(\beta)\right)
$$

where $\beta=h \sqrt{\alpha t} / k$. With the knowledge of one time-temperature pair $\left(t, T_{w}\right)$, the heat transfer coefficient $h$ can be found from any error minimization routine. A typically jet impingement setup involving this technique is shown below. Examples of a detailed heat transfer coefficient obtained through this technique are shown in Figure 3 [21].

More details about this method through studies conducted by the authors can be found in [22]. The uncertainty analysis for this method is presented in detail in $[23,24]$ and finer details about LC calibration is presented in [25]. 

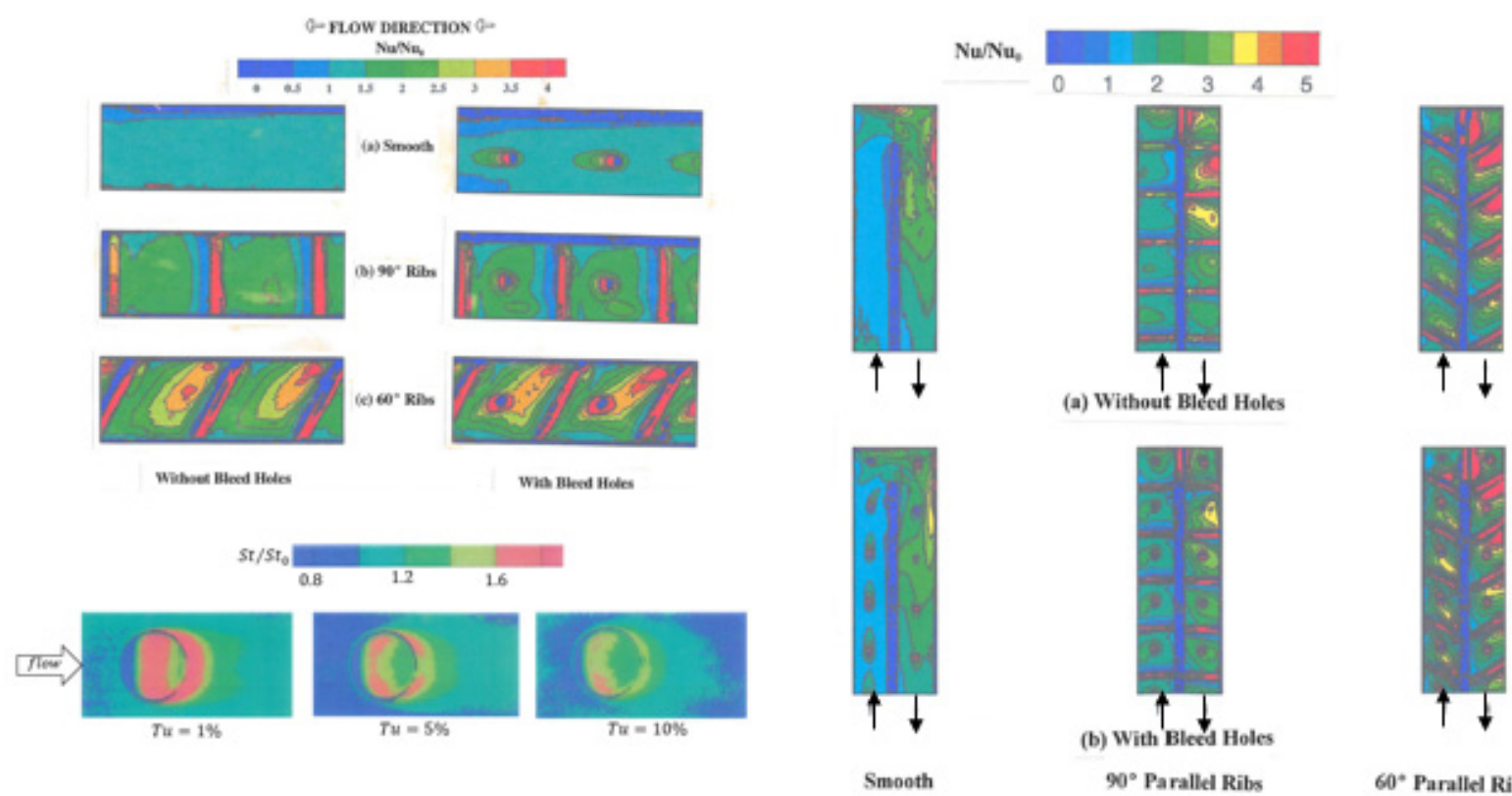

$60^{*}$ Parallel Ribs

Figure 3. Detailed map of the normalized convective heat transfer coefficient $h\left(\mathrm{~W} / \mathrm{m}^{2} \mathrm{~K}\right)$ in the form of $N u$ and $S t$ in rib turbulators/dimple-based cooling configurations [21] (original figures contributed by the 1st author, Ekkad, S.V.).

\subsubsection{Transient Heat Transfer: Simultaneous Determination of $h$ and $\eta$}

Simultaneous determination $h$ and $\eta$ in a single transient experiment was originally proposed by Vedula at Arizona State University along with D.E. Metzger [26]. In filmcooling scenarios, the coolant layer injected into the hot gas path, which protects the outer skin of the turbine airfoil, also enhances the heat transfer between hot gases and the outer skin. Hence, it is imperative to determine the Net Heat Flux Reduction (NHFR) in the presence of film cooling, which is essentially a function of both $h$ and $\eta$. This necessity makes the method proposed in [26] very relevant even in modern times. Although most of the recent investigations have been on experimental determination of adiabatic film cooling effectiveness through Pressure Sensitive Paints (PSP) (for details, see [27]), there exists a need to determine $h$ as well in order to address the full picture of heat transfer in a three-temperature problem, as the one in film cooling. There are pros and cons of the entire heat transfer-based experiments to determine $\eta$ as compared to the PSP technique, where the PSP technique can also provide a detailed $\eta$ map that is free from any lateral conduction effects (particularly in vicinity of film injection). The following is a brief description of the methodology presented in [26] and later evaluated in greater detail in [28].

For a time-varying mainstream temperature, the wall temperature evolution can be presented as follows, after applying Duhamel's superposition principle in Equation (2).

$$
T_{w}=T_{i}+\sum_{j=1}^{N}\left[1-\exp \left(\frac{h^{2} \alpha\left(t-\tau_{j}\right)}{k_{s}^{2}}\right) \operatorname{erfc}\left(\frac{h \sqrt{\alpha\left(t-\tau_{j}\right)}}{k_{s}}\right)\right]\left[\Delta T_{m(j, j-1)}\right]
$$

Equation (2) can be extended to a three-temperature problem (Equation (4)) by replacing $T_{m}$ by $T_{f}$, where adiabatic film cooling effectiveness $\eta=\left(T_{f}-T_{m}\right) /\left(T_{c}-T_{m}\right)$, and where $T_{c}$ is the coolant injection temperature.

$$
T_{w}=T_{i}+\left[1-\exp \left(\frac{h^{2} \alpha(t)}{k_{s}^{2}}\right) \operatorname{erfc}\left(\frac{h \sqrt{\alpha(t)}}{k_{s}}\right)\right]\left(\eta T_{c}+(1-\eta) T_{m}-T_{i}\right)
$$

Equations (3) and (4) essentially comprises of two unknowns that can be found with the knowledge of two time-wall temperature pairs. In LCT, these two distinct occurrences 
can be the red start/peak and green start/peak. However, these two occurrences would not be significantly apart from each other and may lead to large errors. The following additional methods address this issue in the above technique for the determination of $h$ and $\eta$. Note that the above issue can be readily solved if infrared thermography is adopted, since in that case, two wall temperatures can be chosen such that they are sufficiently far apart in terms of their occurrence. Or even further, one does not need to be limited by just two wall temperature choices, since IRT provides high temporal resolution measurements that can facilitate regression analysis for the simultaneous determination of $h$ and $\eta$.

\subsubsection{Transient Heat Transfer: $h$ and $\eta$ Determination through Two Separate Experiments}

Ekkad and Han [18] presented two transient experiment method to determine $h$ and $\eta$. The first experiment is carried out with just the mainstream flow heated to a desired temperature while the coolant is supplied at the room temperature. In the second experiment, both the mainstream and coolant are heated to the same desired temperature. The above two experiments' wall temperature evolution with time can be presented by Equations (5) and (6) below.

$$
\begin{gathered}
T_{w}=T_{i, 1}+\sum_{j=1}^{N}\left[1-\exp \left(\frac{h^{2} \alpha\left(t_{1}-\tau_{j}\right)}{k_{s}^{2}}\right) \operatorname{erfc}\left(\frac{h \sqrt{\alpha\left(t_{1}-\tau_{j}\right)}}{k_{s}}\right)\right]\left[\eta T_{c, 1}+(1-\eta)\left(\Delta T_{m, 1}\right)_{j}\right] \\
T_{w}=T_{i, 2}+\sum_{j=1}^{N}\left[1-\exp \left(\frac{h^{2} \alpha\left(t_{2}-\tau_{j}\right)}{k_{s}^{2}}\right) \operatorname{erfc}\left(\frac{h \sqrt{\alpha\left(t_{2}-\tau_{j}\right)}}{k_{s}}\right)\right]\left[\eta\left(\Delta T_{c, 2}\right)_{j}+(1-\eta)\left(\Delta T_{m, 2}\right)_{j}\right]
\end{gathered}
$$

Equations (5) and (6) can be iteratively solved to determine $h$ and $\eta$. In this method, the same wall temperature is tracked, and two equations are created by running two separate transient heat transfer experiments. Figure 4 shows the detailed map of $h$ and $\eta$ obtained from the above procedure for air and $\mathrm{CO}_{2}$.

\subsubsection{Hybrid Step Heating Method Using Heater Foil for $h$ Determination}

Wolfersorf et al. [29] presented a novel transient step heating technique where a heated foil was glued onto plexiglass, which was modeled as a one-dimensional semi-infinite solid. This method had several benefits as it did not require massive heat input to raise the fluid temperature to a point such that the reference wall temperature is reached in a suitable time (neither too slow nor too fast), and second, this method does not even require liquid crystal color change to wall temperature calibration. In this technique, liquid crystals simply served the purpose of indicating a certain color change behavior and this incidence during the transient experiment was used simply as an isotherm.

In this method, a step heating condition is imposed at the beginning of the transient experiment with the desired flow conditions, and after a certain time (when all pixels have crossed the color indicator point), the heat flux is reduced to a lower value, which essentially drives the wall temperature in the opposite direction. With the knowledge of time taken to reach a certain color indication event during the two continuous heating stages and the instance at which the heat flux was reduced, local heat transfer coefficients were obtained for each pixel whose color change was captured. 


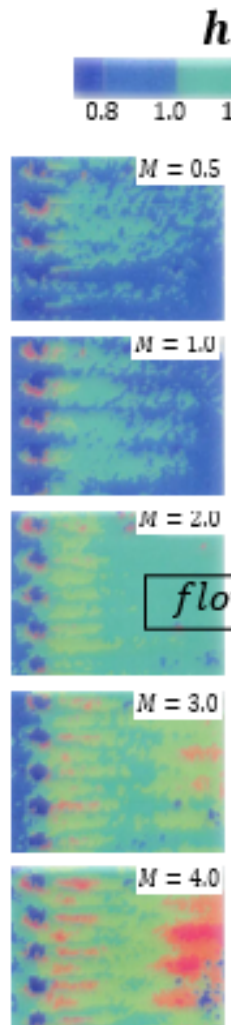

Air $h / h_{0}$
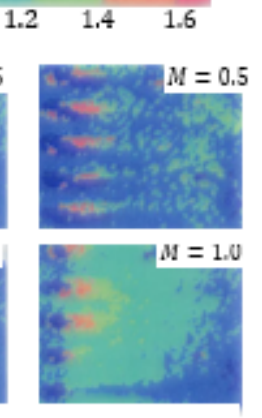

$M=2.0$
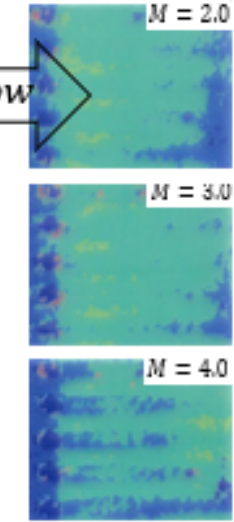

$\mathrm{CO}_{2}$

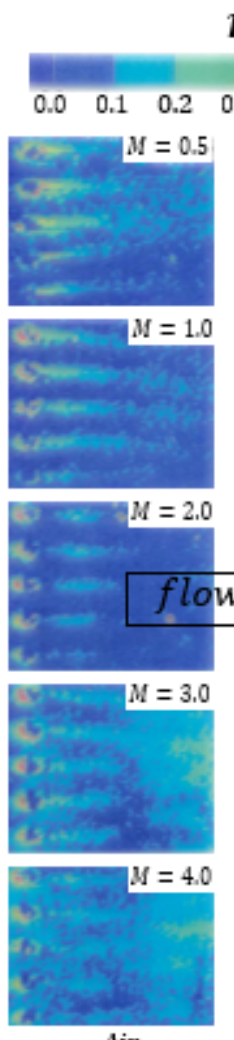

Air

\section{$\eta$}
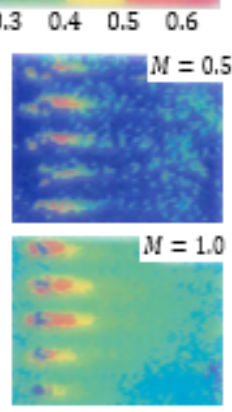

$M=2.0$
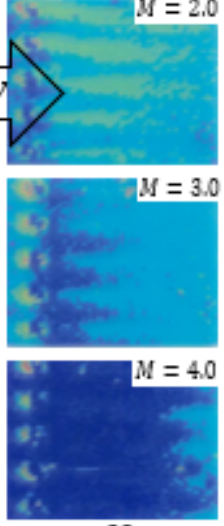

$\mathrm{CO}_{2}$

Figure 4. Detailed map of $h$ and $\eta$ obtained via two separate transient heat transfer experimental methodologies [21] (original figures contributed by the 1st author, Ekkad, S.V.).

Heat diffusion in the solid treated as one-dimensional semi-infinite is given by

$$
\frac{\partial T}{\partial t}=\alpha \frac{\partial^{2} T}{\partial y^{2}}(0<y<\infty)
$$

where the initial condition is $T(y, t=0)=T_{0}$ and the two closure boundary conditions are

$$
\begin{gathered}
-k \frac{\partial T(y=0, t)}{\partial y}=q-h\left(T_{w}-T_{g}\right) 0<t<t_{u} \\
-k \frac{\partial T(y=0, t)}{\partial y}=\in q-h\left(T_{w}-T_{g}\right) t>t_{u}
\end{gathered}
$$

For the special case of $T_{0}=T_{g}$, the Carslaw and Jaeger [30] solution can be rewritten for the two phases of heating during a single transient test as,

$$
\begin{gathered}
h \frac{T_{w}-T_{0}}{q}=1-e^{h^{2} t / k} \operatorname{erfc}\left(\frac{h \sqrt{t}}{\sqrt{k}}\right) 0<t<t_{u} \\
h \frac{T_{w}-T_{0}}{q}=\epsilon-e^{h^{2} t / k} \operatorname{erfc}\left(\frac{h \sqrt{t}}{\sqrt{k}}\right)+(1-\epsilon) e^{h^{2}\left(t-t_{u}\right) / k} \operatorname{erfc}\left(\frac{h \sqrt{t-t_{u}}}{\sqrt{k}}\right) t>t_{u}
\end{gathered}
$$

For the same wall temperature at two time instances, $t_{1}$ and $t_{2}$, Equations (10) and (11) can be equated to each other (Equation (12)), where the only unknown to be found is $h$.

$$
1-e^{h^{2} t_{1} / k} \operatorname{erfc}\left(\frac{h \sqrt{t_{1}}}{\sqrt{k}}\right)=\epsilon-e^{h^{2} t_{2} / k} \operatorname{erfc}\left(\frac{h \sqrt{t_{2}}}{\sqrt{k}}\right)+(1-\epsilon) e^{h^{2}\left(t_{2}-t_{u}\right) / k} \operatorname{erfc}\left(\frac{h \sqrt{t_{2}-t_{u}}}{\sqrt{k}}\right)
$$


As inferred from Equation (11), $h$ can be determined with the knowledge of $t_{1}, t_{u}, t_{2}$ and $\in$.

Note: There was a discussion published in ASME's Journal of Heat Transfer [31], where the authors in [31] presented a proof that the equations derived by Wolfersdorf et al. [29] for $t>t_{u}$ was incorrect. However, the original authors [29] refuted their [31] claims and established that the originally presented equations were accurate. No further discussion was found. Hence the reader can use Equation (13) for heat transfer coefficient calculations.

\subsubsection{Transient LCT Using Time-Varying Surface Heat Flux for Local $h$ and $\eta$ Determination}

Vogel et al. [32] presented a novel transient heater foil technique involving liquid crystal to determine both $h$ and $\eta$. The heat diffusion equation, initial condition and boundary conditions were similar to that of Wolfersdorf et al. [29], except that the surface boundary condition was changed to include the effects of the coolant injection by introducing a normalized temperature $\eta$. An expression for wall temperature evolution was derived and a regression technique was used to determine $h$ and $\eta$ with the knowledge of applied heat flux (q). For details, see [32].

\subsubsection{Transient LCT Using Time-Varying Surface Heat Flux for Local $h$ Determination}

Recently, Schmid et al. [33] presented a novel transient surface heat flux method used in conjunction with LC to determine the local $h$ for a single jet impingement configuration. A time-varying surface heat flux technique was adopted. The governing equation for heat diffusion into the PMMA solid, initial condition and boundary conditions were the same as presented in Equations (7)-(9). Solid temperature evolution with time at any location in the thickness was derived in Laplace space and applying inverse Laplace transformation to obtain

$T(z, t)-T_{0}=-\gamma\left(T_{0}-T_{g}\right)\left[\operatorname{erfc}(a)-e^{b} \operatorname{erfc}(a+c)\right]+\frac{q_{0}}{k \alpha^{2}}\left[\frac{\alpha}{\left(-\frac{h}{k}\right)^{3}} e^{b} \operatorname{erfc}(a+c)-\frac{\alpha}{\left(-\frac{h}{k}\right)^{3}} \sum_{r=0}^{2}(-2 c)^{r} i^{r} \operatorname{erfc}(a)\right]$

where $\gamma$ was $\left(T_{a w}-T_{r}\right) /\left(T_{g}-T_{0}\right)$, which took care of the jet entrainment effect. Here $T_{r}$ was the jet recovery temperature. Further, $a=z / 2 \sqrt{\alpha t}, b=(h z / k)+\alpha t(h / k)^{2}, c=$ $h / k \sqrt{\alpha t}$ and $\mathrm{z}$ is the direction of heat diffusion into the solid. This technique also yields the local convective heat transfer coefficient and addresses an important aspect in impingement heat transfer studies through transient experiments, i.e., the effect of jet entrainment on the choice of the reference fluid temperature. In the steady-state experiments carried out by Goldstein and Behbahani [34], adiabatic wall temperature was used and this method was adopted by many others under similar experimental settings. Using adiabatic wall temperature as a reference fluid temperature provides consistency to the reported $h$ while in short duration transient experiments there is always a debate on the reference fluid temperature choice, particularly so for jet impingement, where typically the jet total temperature is used. However, this choice does not necessary bring out the true driving temperature potential particularly in the wall jet region for a single jet case or between two adjacent jets in array jet impingement systems. For a comprehensive discussion on adiabatic wall temperature and its benefits, the reader is referred to Moffat [35].

\subsection{Recent Advancements in Liquid Crystal Thermography-Based Measurement Techniques}

The experimental methods detailed above are conventional and are used widely to date. However, there are certain limitations of liquid crystals in terms of its sensitivity towards the camera viewing angle, calibration, aging, one-dimensional semi-infinite assumption, etc. This sub-section provides an account of some of the recent efforts where 
these effects were investigated as well as novel methods involving LCT that recently have been developed.

Triple layer of liquid crystals: Terzis et al. [36] employed three subsequent layers of thermochromic liquid crystals for enhanced accuracy in the determination of the heat transfer coefficient in a single row of impinging jets.

Jet impingement configurations tend to result in very high and very low heat transfer zones on the target wall and using a single layer of liquid crystal with one time-temperature event used for calculation of the heat transfer coefficient in turn results in very short or very long time values for certain pixels to reach a reference wall temperature. For instance, a pixel at the jet stagnation point will take significantly less time to reach a certain wall temperature as compared to a pixel in the wall jet region or mid-point between two adjacent jets. The authors in [36] demonstrated that triple-layer liquid crystals allow the flexibility to calculate three values of the heat transfer coefficient for each pixel since three timetemperature pair information is available by calibrating the peak green intensity with the thermocouple-measured wall temperature. They also cautioned about accounting for the thickness of the liquid crystals to avoid significantly underestimating the heat transfer coefficient values. More details about the effects of LC coating thickness as well as the black paint coating thickness can be found in [37].

On the consideration of lateral conduction in conventional 1-d semi-infinite modeling: The LC-based techniques mentioned above essentially rely on the assumption that the heat diffusion in the solid is strictly one dimensional for short-duration experiments. Such assumptions work well for some special scenarios, such as flow over a flat plate, or cases where large gradients in true $h$ does not exist. However, in most cases involving enhanced heat transfer, there exists strong gradients in local $h$ and hence ignoring lateral conduction effects may lead to erroneous results. Some of the earlier investigations on evaluating the difference in $h$ for jet impingement systems when lateral conduction effects were accounted for were carried out by [38,39]. More recently, Brack et al. [40] investigated the validity of this assumption for a test case of flow over a flat plate featuring a Vortex Generator. The authors carried out both transient infrared thermography and transient LCT experiments to compare the $h$ values obtained via the 1-D semi-infinite conduction modeling as well as 3-D conduction modeling. It was found that IR- and LC-based techniques agreed well with each other, and that $h$ through 1-D assumption was consistently higher than that obtained through 3-D modeling for three points investigated downstream of the Vortex Generator. In a follow-up work [41], the authors carried out a theoretical analysis to quantity the local differences in $h$ values obtained through the above two approaches for an array of impinging jets out of many other test cases. In their study, the difference in $h$ was negligible in the stagnation region; however, in low heat transfer zones between adjacent jets, the $h$ values obtained through a 1-D assumption was about $10 \%$ higher than that obtained through 3-D modeling. Further, at the stagnation region, $h$ obtained through 3-D modeling was slightly higher than that obtained through 1-D modeling. Ahmed et al. [42] investigated the differences between $h$ through above two conduction modeling approaches and found that the $h$ obtained through 3-D modeling was consistently higher than that obtained through 1-D. In their study, the $h$-guess method prescribed in [38] was employed and the results were presented for a single row of jets with mostly high heat transfer zones as opposed to the case of [41], where special emphasis was provided to the low heat transfer zones surrounding the stagnation region. Clearly, more research needs to be carried out to explore the aspect of modeling 3-D heat diffusion for more accurate determination of the local heat transfer coefficients.

$\boldsymbol{h}$ determination on 3D geometries: In enhanced heat transfer research, installation of extended surfaces on a flat surface is a common method to increase the local heat transfer. For example, in the case of flow through a square duct, periodical placement of rib turbulators enhances the heat transfer between two adjacent ribs due to a separationreattachment mechanism. LCT is typically employed to measure the local $h$ between two ribs where the surface of interest is essentially smooth and flat. However, the heat transfer 
levels at the rib surface itself is several folds higher than that accomplished in its pitches. LCT with 1-D semi-infinite conduction modeling has the limitation that it can be employed to measure the local heat transfer at the rib surfaces, since it will violate the assumption of strictly 1-D heat diffusion. Such studies where rib surfaces are excluded in the reporting of pitch-averaged Nusselt number result in significant under-reporting of the actual $h$. Such a problem does not exist in the traditional copper-block heater experiments that capture heat transfer occurring at the rib surface; it also is inclusive of the conjugate effects of extended surfaces. Although the aim of the LCT-1D approach is to capture the local $h$ not including the conjugate effects, it is not capable of capturing the same at the rib surfaces. To address this limitation, a recent study by Ryley et al. [43] from the University of Oxford demonstrates a combined approach of LCT and Finite Element Analysis to capture the local $h$ at the 45-degree inclined rib turbulators. The above technique is of the nature of post-processing of the liquid crystal color change time-history, where it is used a reference or true wall temperature evolution with time, and a subsequent iterative Finite Element Analysis (FEA) approach is employed to guess the true $h$ responsible for such a local wall temperature time evolution that has reduced the effects of lateral conduction. A corner correction approach was presented earlier by Jiang et al. [44] where errors incurred due to 1-D semi-infinite conduction modeling on sharp corner geometries was elaborated as well as a corrective measure was prescribed.

On the reference fluid temperature in internal flow configurations: The local heat transfer coefficient is defined as $h=q^{\prime \prime} /\left(T_{w}-T_{r e f}\right)$, where $T_{r e f}$ is the reference fluid temperature that is driving the wall temperature evolution in a typical transient LC experiment with either step heating/cooling of air as the working fluid. A general practice in such flow scenarios is to use the local bulk fluid temperature as the $T_{r e f}$, since the fluid temperature continuously changes with local streamwise location due to the heat exchange with the duct enclosure walls. In a sufficiently long duct featuring periodically arranged rib turbulators on two opposite walls, the fluid temperature can significantly change from its inlet value, as well as its evolution with time at two streamwise locations far apart from each other can be very different. To this end, typically, a linear interpolation method is adopted [22] to obtain the local bulk fluid temperature at different streamwise locations. In most cases with shorter duct lengths, this method yields in acceptable $T_{r e f}$, with minimal impact on $h$ determination; however, linear interpolation of fluid temperature in the case of a convective-type boundary condition and 1-D semi-infinite conduction modeling, by definition, is not appropriate. Such an interpolation scheme for local $T_{r e f}$ is applicable when the walls of the enclosure are subjected to a constant heat flux boundary condition. For details on the control volume-based energy balance approach, see [45]. Chyu et al. [46] presented four different methods for the determination of the local reference fluid temperature, where it was shown that significant differences in $h$ can be observed with different choices. Although the differential volume-based energy balance approach presented in [46] is better than simple linear interpolation of the bulk fluid temperature between two distant locations, these methods are still based on point measurements by thermocouples. Usually, one thermocouple is installed at the channel centerline and that measurement is assumed to be constant in the plane orthogonal to the mainstream flow at that streamwise location. However, the above assumption is not necessarily true since a fluid temperature closer to the walls is very different when compared to the channel centerline temperature. This issue has been addressed in the following sub-section.

On the validity of point-based local fluid temperature as bulk (or reference) fluid temperature: Jenkins et al. [47] measured local fluid temperatures at different locations in a high aspect ratio (4:1) two-pass channel featuring 45-degree rib turbulators and performed calculations to obtain a full-sweep of the local fluid temperature at different planes in the two-pass channel. An array of $4 \times 4$ thermocouples was installed in one quarter of a plane and the entire time history of the temperatures were recorded as raw data for postprocessing. The authors found that the centerline measured temperature and the reference temperature obtained by full-sweep yield in nearly similar heat transfer coefficients in the 
first passage, where the flow is well mixed and fully-periodic conditions, were achieved. However, due to the 180-degree bend, the flow in the return passage is extremely skewed towards the outer wall of the channel, leading to a highly non-uniform fluid temperature distribution. However, considering the definition of a bulk fluid temperature, one needs to have complete information on the local fluid velocity as well as the local fluid temperature in the entire plane to obtain a more realistic bulk temperature. In [47], although efforts were made to better capture the local fluid temperature variation, it was not coupled with the experimental measurement of local flow velocities, hence the determined reference temperature was still under the assumption that the local fluid temperature was constant on the plane, which is not true. The above factor becomes even more dominant post the 180-bend, and more experimental-numerical studies are recommended to capture the true reference fluid temperature, particularly in the bend and post-bend regions in typical two-passage cooling channels.

On the validity of intercomparison of $h$ obtained through transient LC experiments and steady-state computations: In recent years, there has been a surge in Reynolds Averaged Navier-Stokes (RANS)-based computations to predict the flow-field and wall heat transfer, where validation studies were carried out using $h$ obtained from transient LC experiments [48-52]. Now, usually the RANS-based computational studies are carried out under steady-state conditions with either a constant wall heat flux or constant wall temperature-type boundary condition, while the LC transient experiments have a convection-type boundary condition. To this end, Axtmann et al. [53] carried out an experimental and numerical investigation for determining the local heat transfer coefficient for a staggered array of cylindrical pin fins. The authors in [53] used the non-dimensional temperature (Equation (14)) prescribed by [47] to evaluate the comparability of the steady-state computations with transient experiments.

$$
\Theta=\frac{T_{\text {local }}(t)-T_{\text {out }}(t)}{T_{\text {in }}(t)-T_{\text {out }}(t)}
$$

The streamwise variation in $\Theta$ at different time instances, when compared with a similar analysis from computations, indicated that, firstly, the transient experiment was quasi-steady in nature since the $\Theta$ versus streamwise location trend was time invariant, and this trend was in very close agreement with that of the computationally predicted $\Theta$. Through the above argument, the authors in [53] justified that RANS-based steadystate computations can be used in conjunction with transient LC experiments to better understand the flow and thermal transport.

All the above aspects and techniques are essentially based on step heating or cooling of the air and subsequently routed through the fluid domain, driving the wall temperature to cross the liquid crystal color play band, from where suitable methods are employed to determine $h$ and $\eta$. However, there are scenarios in which achieving a proper step change in the fluid temperature through mesh heaters or thermal reservoirs is not that straightforward; for example, in high mass-flow rate flows. One way to work around this challenge is to adopt a steady-state copper foil heating experiment where wall temperature is still measured by liquid crystal color change processing, and the heat energy is simply used to create a temperature differential between the local wall and fluid temperature. For example, in [54], the authors investigated the local heat transfer characteristics of different rib shapes at very high Reynolds numbers, varying between 100,000 and 500,000. In such experiments, local heat transfer coefficients can be obtained by known wall heat flux, wall temperature and point measurement of fluid temperature; however, steady-state in nature. There are some other novel approaches where transient methods were demonstrated where wall heating was adopted to solve the problem of step heating a large mass flux of air.

\section{Recent Studies Involving Liquid Crystals}

This section presents some recent investigations where liquid crystal thermography was employed for detailed measurements of $h$ and $\eta$. There have been numerous studies 
involving LCT, but our focus is to showcase studies from the past five-year period (2016present).

\subsection{Rib Turbulators}

Liu et al. [55] investigated perforated rib turbulators in a rectangular channel where a steady-state technique was employed, and LC was used to measure the local surface temperature. A sample Nusselt number contour is shown in Figure 5, where it can be seen that the contours are not as sharp as the ones obtained with the transient LC technique, as observed by several researchers in the past [56-58]. A similar contour quality as in Figure 5 was observed by Zhang et al. [54], where the local Nusselt numbers were determined for very high Reynolds numbers for five different rib shapes. The steady-state methodology adopted by Kaewchoothong et al. [59], where the contribution of convection, radiation and, most importantly, conduction losses were removed from the total heat input, resulted in the local heat transfer characteristics being sharper and hence bringing forth the local differences between the different rib shapes. Steady-state heat transfer techniques have strong potential to be developed further since they are also associated with lower overall uncertainties as compared to transient LC techniques.

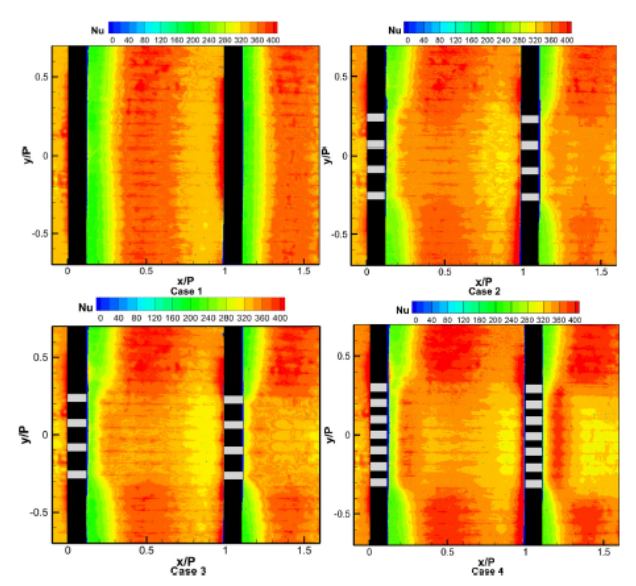

Figure 5. Local Nusselt number contours for perforated rib turbulators [55]. Figure reprinted from an open source.

Truncated prismatic ribs' heat transfer characteristics using LCT was presented by Sharma et al. [60] under transient conditions. The local heat transfer contours were random in nature and not particularly representative of the true fluid phenomena peculiar to the exotic rib shapes investigated in [60]. Multi-passage configurations featuring rib turbulators through transient LC technique was carried out by Guo et al. [61]. Miniaturized W-shaped ribs occupying the entire channel span for a three-passage configuration was investigated by Rao et al. [62].

Criss-cross ribs were investigated by Singh et al. [50], where the ribs were installed in an inline and staggered configuration in a straight duct with a unity aspect ratio, typically found in the mid-chord region of a gas turbine blade. Nusselt number ratios were found to vary between 3.1 to 2.7 for Reynolds number ranging from 30,000 to 60,000 and inline and staggered configurations performed similar to each other. Liou et al. [63] investigated novel wing-shaped turbulators (Figure 6) in a typical two-passage configuration. The authors provided a correlation for the Nusselt number ratio as a function of Reynolds number and pitch-to-channel hydraulic diameter ratio $(\mathrm{p} / \mathrm{d})$. 


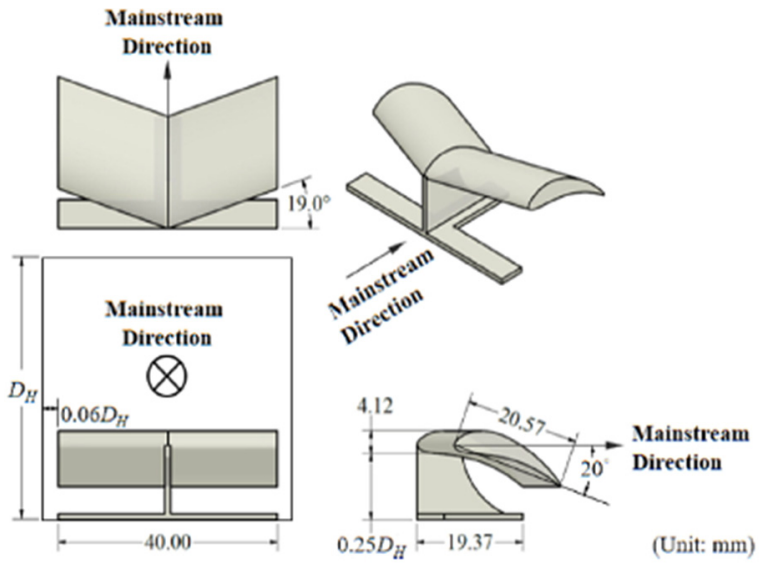

Figure 6. Wing-shaped turbulators. Reprinted with permission: License number 5177110018029.

Promvonge [64] used LCT to present local heat transfer coefficients for arc-shaped baffle turbulators. Eiamsa-ard and Chuwattanakul [65] investigated the local heat transfer characteristics of inclined and transverse twisted-baffles using LC. A maximum thermal hydraulic performance of 1.98 was observed and the local heat transfer behavior of different configurations was presented. The above studies were focused on a particular concept of rib turbulators where channels representative of that found in gas turbine blades were used. However, liquid crystal thermography can be used in even more complex fluid domains, such as the one where an entire blade with different cooling concepts, such as jet impingement, ribs and pin fins, are installed as heat transfer enhancement agents. One such study was recently carried out by Shiau et al. [66] from Texas A\&M University, where a three-passage configuration with $45^{\circ}$ rib turbulators and a trailing edge passage with both ribs and pin-fins was tested. The two $180^{\circ}$ bends were flat and U-shaped, and provisions were provided for blade-tip leakage flows as well. Local heat transfer coefficients were presented on both the pressure and suction side internal surfaces. Such studies provide valuable insights into a more realistic cooling performance of concepts when put together, with local wall temperatures one can expect in an actual gas turbine blade by scaling the laboratory condition results.

The above studies were stationary in nature; however, an actual gas turbine blades undergo high speed rotation as well. There have been several experimental studies in the past where local heat transfer coefficients were determined on the pressure and suction side internal surfaces when subjected to rotation. Under rotating conditions, a combination of Coriolis and centrifugal buoyancy forces modify the local heat transfer characteristics of cooling channels compared to that observed under non-rotating conditions. Knowledge of the local heat transfer coefficients under rotating conditions becomes imperative since the rotation-induced forces not only influence the global cooling levels but also the local heat transfer behavior. To this end, TLC has been used traditionally under rotating conditions in the 1990s till now. In this area, there has been significant advancements in the quality of high-resolution 2D heat transfer distribution.

Singh et al. [48] carried out transient LC experiments under both stationary and rotating conditions for two-pass smooth and V-rib channels for a wide range of flow Reynolds number. For the highest rotation number, the actual rotational speed was 700 RPM. In these experiments, the CCD camera was mounted on top of the cooling channel and was spun along with it. It can be seen that high-resolution data under such complex conditions (high speed rotation) provides valuable insights into the local changes in heat transfer on the pressure and suction sides (Figure 7). For a more detailed review on rotating heat transfer studies involving liquid crystals, the reader is referred to Ekkad and Singh [67]. 

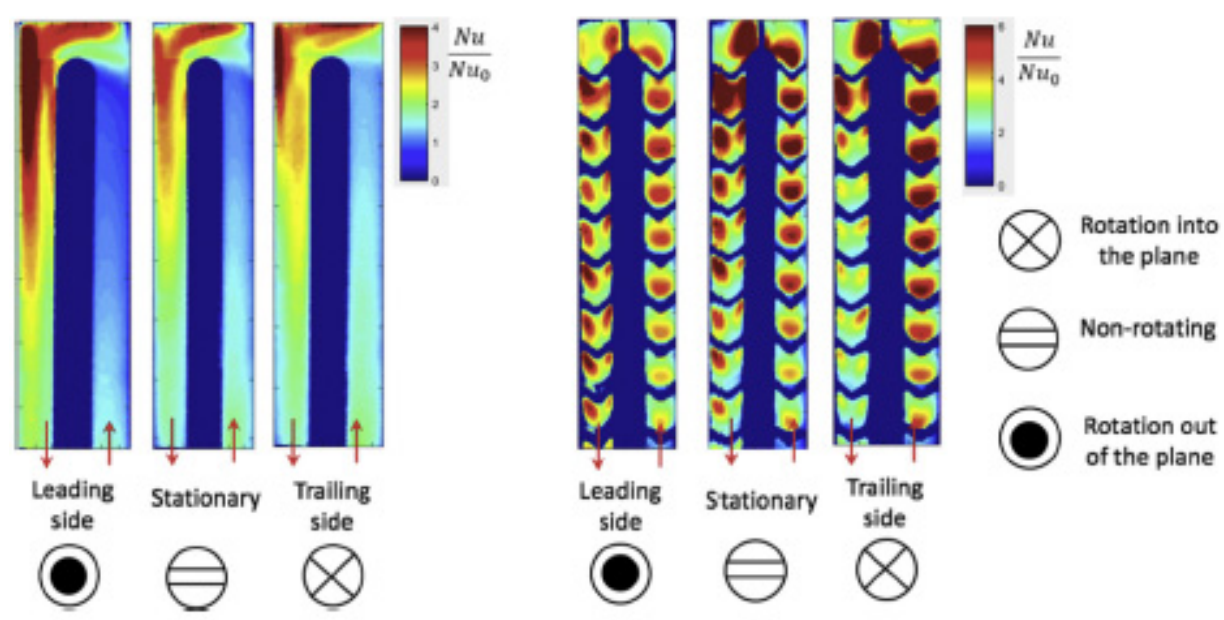

Figure 7. Smooth and ribbed channel heat transfer map under stationary and rotating conditions. Reprinted with permission: License number 5177110161442.

\subsection{Jet Impingement}

Jet impingement is a widely explored topic and TLC's have provided valuable insights into the local heat transfer behavior at the target wall. A detailed review on the jet impingement technology and its state-of-the-art can be found in [68]. In this section, we have presented some recent investigations on jet impingement employing TLC. Chen et al. [69] used multiple liquid crystal color sprays to determine the local heat transfer of impinging jets for three different crossflow schemes. It was shown that multiple TLC case yield similar heat transfer levels as compared to a single TLC case. Chen et al. [70] employed transient liquid crystal thermography for jet impingement onto target surface featuring micro-roughness elements. However, as discussed earlier, geometries with sharp corners when modeled as one-dimensional semi-infinite solids can lead to an erroneous local $h$ distribution. In another study by Chen et al. [71] recently reported the local heat transfer characteristics of a target plate featuring small-height, interconnected V-shaped turbulators, where the jet footprint was at the junction of two adjacent rib turbulators. Effects of spray coating thickness in comparison to rib height was also discussed. Brakmann et al. [72] investigated impingement heat transfer enhancements when detached ribs were mounted on the target wall. Note that in the above studies [69-72], where the target surface features roughness elements, there is a general consensus that roughening the target wall does not necessarily improve the local convective heat transfer coefficient. On the contrary, Singh et al. [73] demonstrated that the heat transfer coefficient actually reduces when the target surface is roughened by micro elements; however, the increase in wetted surface area supersedes this reduction and the overall heat transfer $(\mathrm{hA})$ is enhanced. However, the authors in [73] reported on global heat transfer, including the conjugate effects of the extended surface as well as the endwall (remaining portion of target wall) through steady-state constant heat flux experiments on metal plates. In studies employing liquid crystal thermography with solids modeled as a one-dimensional semi-infinite medium, such conjugate effects cannot be determined.

Rao et al. [74] employed pin fins and effusion holes on the target plate and carried out LC experiments along with computations to understand the heat transfer enhancement mechanisms due to fluid domain modifications.

Another recent study by Madhavan et al. [57] demonstrated the effectiveness of U-shaped crossflow diverters in their effectiveness in preserving the jet effectiveness of rows closer to the exit in a maximum crossflow situation. The authors reported a 9-15\% enhancement in global $h$ at the same pumping power with the target featuring U-shaped diverters as compared to the case without it.

Apart from target surface modification, there are some other techniques that are employed to enhance the impingement heat transfer. Wang et al. [75] employed transient 
liquid crystal thermography for leading edge impingement configuration subjected to normal and tangential jets. Measurements of internal wall temperature were carried out at two viewing angles, $45^{\circ}$ and $90^{\circ}$, relative to the target plate. Tangential injection of coolant had a swirl-type heat transfer enhancement mechanism. Recently, Galeana and Beyene [76] used TLC to measure the local convective heat transfer coefficient in a swirl chamber representative of a blade leading-edge cavity. The crossflow-induced swirl concept originally presented by Pamula et al. [77] was explored by Yang et al. [78] under rotating conditions. A series of impingement effusion cooling studies was recently reported in $[79,80]$.

\subsection{Pin Fins}

Pin fins are typically used for trailing-edge cooling, which has severe space constraints. The trailing-edge region allows a variable cross-section flow path to the incoming coolant, and the pin fins are typically arranged in an inline or staggered formation where the two ends of the pin fins join the pressure and suction sides to offer mechanical strength as well. Pin fin heat transfer has been explored by several researchers in the past through thermocouple [81,82], mass transfer techniques [83] and liquid crystals $[84,85]$. The above studies were carried out prior to 2000. More recently, with the advancements in instrumentation, TLC experiments have also been carried out under rotating conditions, e.g., [86-88]. For a more detailed review on TLC implementation under rotating conditions, see [67].

Some recent investigations into trailing-edge pin fin cooling include Liang et al. [89], where different pin fins were arranged in a wedge-shaped channel in a staggered form. The coolant ejection was on the lateral end similar to the typical trailing edge cooling design in gas turbine blades. Figure 8 shows a normalized Nusselt number distribution for different pin fin shapes, where high-resolution local heat transfer data were presented. Through these contours, one can visualize the highly localized cooling behavior and designers can modify the relative arrangements on pin fins to get the desired overall cooling as well as local blade temperature.

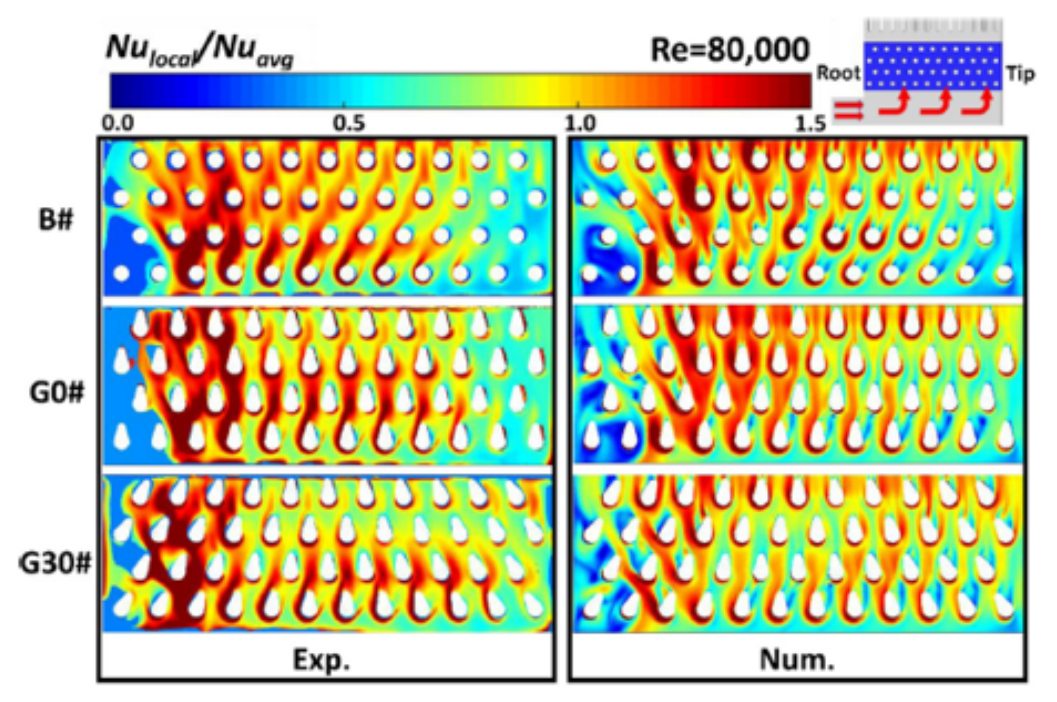

Figure 8. Normalized local Nusselt number ratio at $\operatorname{Re}=80,000$ [89]. Reprinted with permission: License number 5177210455931.

\subsection{Endwall Heat Transfer and Blade Film Cooling}

Liquid crystal thermography has been used extensively in external flow studies as well. We have grouped endwall and film cooling together since they essentially fall in the hot gas path, and both endwall and blade outer skin are often cooled by an array of film holes through coolant injection. Most of the studies on endwalls have been focused on measurement of local heat transfer coefficients and ways to reduce the heat transfer since it is subjected to hot gases. 
Recently, Hussain et al. [90] presented a novel flow control concept to alter the boundary layer flows around an airfoil through vortex structure modification. Local Nusselt numbers were calculated by measuring the local wall temperatures using steady-state liquid crystal thermography.

Ratto et al. [91] also used steady-state liquid crystal thermography to measure the local heat transfer characteristics and also accounted for the lateral conduction effects. Liu et al. [92] investigated the modified endwall heat transfer at a model outlet guide vane when a pocket cavity was placed slightly upstream, with the help of a steady-state LC technique. Prior to the above study [93], the authors replaced the outlet guide vane with a bluff body (circular cylinder) with a pocket cavity upstream and measured the local heat transfer coefficient around it [94]. Tamunobere and Acharya [95] carried out transient LC experiments to measure turbine shroud heat transfer and film cooling under rotating conditions.

The above studies were based on the steady-state LC technique. The following paragraph documents the transient LC technique used for endwall heat transfer. Liu et al. [95] employed the transient LC technique to measure the local heat transfer coefficient in the endwall region between two airfoils where the coolant presence was also maintained via an array of film holes (Figure 9). Hayes et al. [96] employed a transient LC technique to determine both $h$ and $\eta$ for novel anti-vortex film holes at varying blowing ratios (Figure 10).

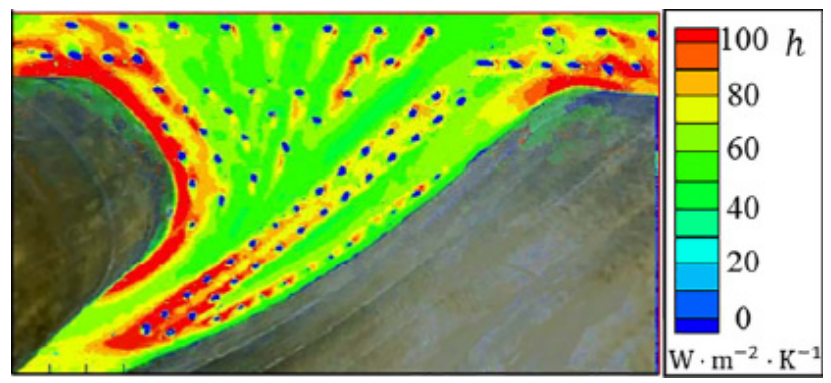

Figure 9. Local heat transfer coefficient in presence of film holes [95]. Reprinted with permission: License number 5177210786902.
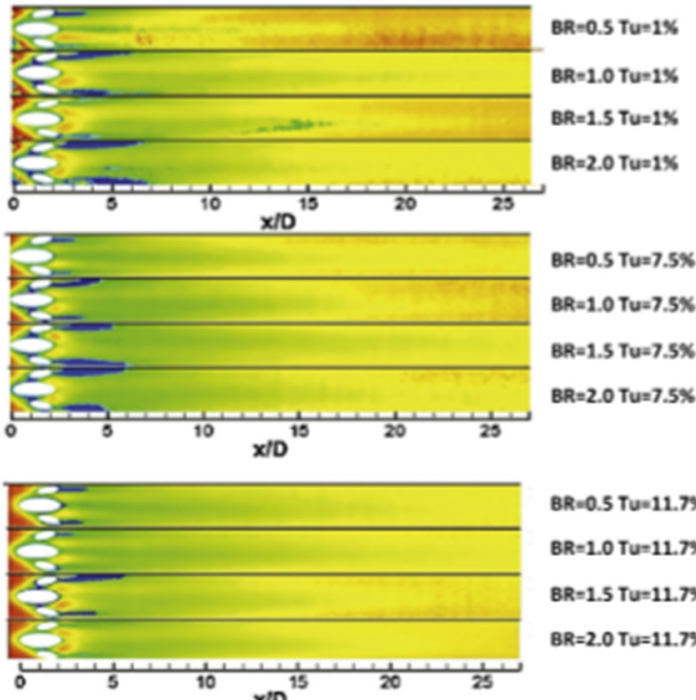

BR=0.5 Tu=11.7\% $B R=1.0$ Tu $=11.7 \%$ $B R=1.5$ Tu=11.7\% $B R=2.0 \quad T u=11.7 \%$
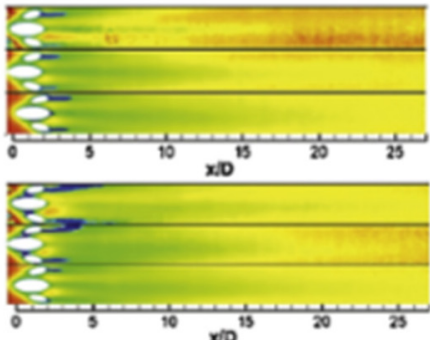

\section{B}
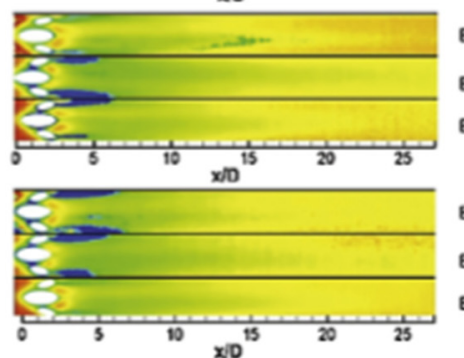

BR=0.5 Tu=1\%

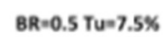

BR=0.5 TU=11.7\%

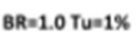

$8 R=1.0$ Tu=7.5\%

BR=1.0 Tu= $11.7 \%$

$8 R=1.5$ Tu=1\%

$B R=1.5 T u=7.5 \%$

$B R=1.5 T u=11.7 \%$

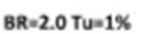

BR $=2.0$ Tu $=7.5 \%$

$B R=2.0 \quad T u=11.7 \%$

(b)

Figure 10. Local adiabatic film cooling effectiveness measured by a transient LC technique [96], (a) $h$, (b) $\eta$. Reprinted with permission: License number 5177211004715. 
The results were compared against the originally presented anti-vortex hole film cooling performance through infrared thermography by Dhungel et al. [97]. The authors in [96] also presented the net heat flux reduction resulting from the installation of the anti-vortex holes with the knowledge of both $h$ and $\eta$. Some other recent investigations employing the transient LC technique for $h$ and $\eta$ calculations include [98-100].

\section{Concluding Remarks}

This paper presents a review of the measurement techniques based on liquid crystal thermography for gas turbine heat transfer applications. A critical analysis of different methods is presented as well as some new studies on technique advancements. The transient techniques developed in the 1990s based on the analytical expressions of heat conduction, originally derived by Carslaw and Jaeger [30] and with inclusion of Duhamel's superposition, are still widely used in almost the same manner. With the advancements in instrumentation, such as high spatial and temporal resolution CCD cameras and fastresponse thermocouples, the quality of 2-D heat transfer data has most certainly improved over the years. Overall, LCT continues to be used as a robust method for high-resolution 2-D heat transfer measurements in gas turbine applications and is also being adopted in other general heat transfer areas as well.

Funding: This research received no external funding.

Conflicts of Interest: The authors declare no conflict of interest.

\section{References}

1. Han, J.-C. Fundamental Gas Turbine Heat Transfer. J. Therm. Sci. Eng. Appl. 2013, 5, 021007. [CrossRef]

2. Han, J.-C.; Dutta, S.; Ekkad, S. Gas Turbine Heat Transfer and Cooling Technology, 2nd ed.; CRC Press: Boca Raton, FL, USA, 2012.

3. Ireland, P.T.; Jones, T.V. The Measurement of Local Heat Transfer Coefficients in Blade Cooling Geometries, In AGARD Heat Transfer and Cooling in Gas Turbines 8 p (SEE N86-29823 21-07). 1985. Available online: https:/ / ui.adsabs.harvard.edu/abs/19 85htcg.agar..... (accessed on 30 August 2021).

4. Goldstein, R.J.; Franchett, M.E. Heat Transfer From a Flat Surface to an Oblique Impinging Jet. J. Heat Transf. 1988, 110, 84-90. [CrossRef]

5. Baughn, J.W. Liquid crystal methods for studying turbulent heat transfer. Int. J. Heat Fluid Flow 1995, 16, 365-375. [CrossRef]

6. Metzger, D.E.; Bunker, R.S.; Bosch, G. Transient Liquid Crystal Measurement of Local Heat Transfer on a Rotating Disk with Jet Impingement. J. Turbomach. 1991, 113, 52-59. [CrossRef]

7. Ekkad, S.V.; Han, J.-C. Detailed heat transfer distributions in two-pass square channels with rib turbulators. Int. J. Heat Mass Transf. 1997, 40, 2525-2537. [CrossRef]

8. Camci, C.; Glezer, B.; Owen, J.M.; Pilbrow, R.G.; Syson, B.J. Application of Thermochromic Liquid Crystal to Rotating Surfaces. J. Turbomach. 1998, 120, 100-103. [CrossRef]

9. Taslim, M.E.; Li, T.; Spring, S.D. Measurements of Heat Transfer Coefficients and Friction Factors in Passages Rib-Roughened on All Walls. J. Turbomach. 1998, 120, 564-570. [CrossRef]

10. Méndez, M.P.; Martinez, D.R.; King, S.M. pH-induced size changes in solutions of cholesteric liquid- crystal polymers studied by SANS. J. Phys. Conf. Ser. 2014, 554, 012011. [CrossRef]

11. Poser, R.; von Wolfersdorf, J. Liquid Crystal Thermography for Transient Heat Transfer Measurements in Complex Internal Cooling Systems; Begel House Inc.: Danbury, CT, USA, 2009. [CrossRef]

12. Camci, C.; Kim, K.; Hippensteele, S.A.; Poinsatte, P.E. Evaluation of a Hue Capturing Based Transient Liquid Crystal Method for High-Resolution Mapping of Convective Heat Transfer on Curved Surfaces. J. Heat Transf. 1993, 115, 311-318. [CrossRef]

13. Hay, J.L.; Hollingsworth, D.K. A comparison of trichromic systems for use in the calibration of polymer-dispersed thermochromic liquid crystals. Exp. Therm. Fluid Sci. 1996, 12,1-12. [CrossRef]

14. Kodzwa, P.M.; Eaton, J.K. Angular effects on thermochromic liquid crystal thermography. Exp. Fluids 2007, 43, 929-937. [CrossRef]

15. Abdullah, N.; Talib, A.R.A.; Jaafar, A.A.; Salleh, M.A.M.; Chong, W.T. The basics and issues of Thermochromic Liquid Crystal Calibrations. Exp. Therm. Fluid Sci. 2010, 34, 1089-1121. [CrossRef]

16. Cukurel, B.; Selcan, C.; Arts, T. Color theory perception of steady wide band liquid crystal thermometry. Exp. Therm. Fluid Sci. 2012, 39, 112-122. [CrossRef]

17. Ireland, P.T.; Jones, T.V. Liquid crystal measurements of heat transfer and surface shear stress. Meas. Sci. Technol. 2000, 11, 969-986. [CrossRef]

18. Ekkad, S.V.; Han, J.-C. A transient liquid crystal thermography technique for gas turbine heat transfer measurements. Meas. Sci. Technol. 2000, 11, 957-968. [CrossRef] 
19. Abuaf, N.; Bunker, R.; Lee, C.P. Heat Transfer and Film Cooling Effectiveness in a Linear Airfoil Cascade. J. Turbomach. 1997, 119, 302-309. [CrossRef]

20. Abuaf, N.; Bunker, R.S.; Lee, C.P. Effects of Surface Roughness on Heat Transfer and Aerodynamic Performance of Turbine Airfoils. J. Turbomach. 1998, 120, 522-529. [CrossRef]

21. Ekkad, S.V. Gas Turbine Film Cooling and Heat Transfer Measurements Using a Transient Liquid Crystal Technique. Ph.D. Thesis, Texas A\&M University, College Station, TX, USA. Available online: https://www.proquest.com/docview/304224159/abstract/ 9362FB04B84D457DPQ/1 (accessed on 7 October 2021).

22. Singh, P.; Ekkad, S. Experimental study of heat transfer augmentation in a two-pass channel featuring V-shaped ribs and cylindrical dimples. Appl. Therm. Eng. 2017, 116, 205-216. [CrossRef]

23. Yan, Y.; Owen, J.M. Uncertainties in transient heat transfer measurements with liquid crystal. Int. J. Heat Fluid Flow 2002, 23, 29-35. [CrossRef]

24. Owen, J.M.; Newton, P.J.; Lock, G.D. Transient heat transfer measurements using thermochromic liquid crystal. Part 2: Experimental uncertainties. Int. J. Heat Fluid Flow 2003, 24, 23-28. [CrossRef]

25. Kakade, V.U.; Lock, G.D.; Wilson, M.; Owen, J.M.; Mayhew, J.E. Accurate heat transfer measurements using thermochromic liquid crystal. Part 1: Calibration and characteristics of crystals. Int. J. Heat Fluid Flow 2009, 30, 939-949. [CrossRef]

26. Vedula, R.P. Film Cooling Effectiveness and Heat Transfer Measurements Using Thermochromic Liquid Crystals. Ph.D. Thesis, Arizona State University, Tempe, AZ, USA. Available online: https://www.proquest.com/docview/303664978/abstract/7927F1 874B7E4EBCPQ/1 (accessed on 25 August 2021).

27. Han, J.-C.; Rallabandi, A. Turbine Blade Film Cooling Using Psp Technique. Front. Heat Mass Transf. (FHMT) 2010, 1. Available online: http:/ /ww.thermalfluidscentral.org/journals/index.php/Heat_Mass_Transfer/article/view/71 (accessed on 25 August 2021). [CrossRef]

28. Ekkad, S.V.; Ou, S.; Rivir, R.B. A Transient Infrared Thermography Method for Simultaneous Film Cooling Effectiveness and Heat Transfer Coefficient Measurements From a Single Test. J. Turbomach. 2004, 126, 597-603. [CrossRef]

29. von Wolfersdorf, J.; Hoecker, R.; Sattelmayer, T. A Hybrid Transient Step-Heating Heat Transfer Measurement Technique Using Heater Foils and Liquid-Crystal Thermography. J. Heat Transf. 1993, 115, 319-324. [CrossRef]

30. Carslaw, H.S.; Jaeger, J.C.; Conrad, J.J.J. Conduction of Heat in Solids; Clarendon Press: London, UK, 1959.

31. Bieniasz, B.; Smusz, R. Discussion: “A Hybrid Transient Step-Heating Heat Transfer Measurement Technique Using Heater Foils and Liquid-Crystal Thermography" (von Wolfersdorf, J., Hoecker, R. and Sattelmayer, T., 1995, ASME J. Heat Transfer, 115, pp. 319-324. J. Heat Transf. 1996, 118, 265-266. [CrossRef]

32. Vogel, G.; Graf, A.B.A.; von Wolfersdorf, J.; Weigand, B. A Novel Transient Heater-Foil Technique for Liquid Crystal Experiments on Film-Cooled Surfaces. J. Turbomach. 2002, 125, 529-537. [CrossRef]

33. Schmid, J.; Gaffuri, M.; Terzis, A.; Ott, P.; von Wolfersdorf, J. Transient liquid crystal thermography using a time varying surface heat flux. Int. J. Heat Mass Transf. 2021, 179, 121718. [CrossRef]

34. Goldstein, R.J.; Behbahani, A.I. Impingement of a circular jet with and without cross flow. Int. J. Heat Mass Transf. 1982, 25, 1377-1382. [CrossRef]

35. Moffat, R.J. What's new in convective heat transfer? Int. J. Heat Fluid Flow 1998, 19, 90-101. [CrossRef]

36. Terzis, A.; Bontitsopoulos, S.; Ott, P.; von Wolfersdorf, J.; Kalfas, A.I. Improved Accuracy in Jet Impingement Heat Transfer Experiments Considering the Layer Thicknesses of a Triple Thermochromic Liquid Crystal Coating. J. Turbomach. 2015, 138, 021003. [CrossRef]

37. Schulz, S.; Brack, S.; Terzis, A.; von Wolfersdorf, J.; Ott, P. On the effects of coating thickness in transient heat transfer experiments using thermochromic liquid crystals. Exp. Therm. Fluid Sci. 2016, 70, 196-207. [CrossRef]

38. Lin, M.; Wang, T. A transient liquid crystal method using a 3-D inverse transient conduction scheme. Int. J. Heat Mass Transf. 2002, 45, 3491-3501. [CrossRef]

39. Wang, T.; Lin, M.; Bunker, R.S. Flow and heat transfer of confined impingement jets cooling using a 3-D transient liquid crystal scheme. Int. J. Heat Mass Transf. 2005, 48, 4887-4903. [CrossRef]

40. Brack, S.; Poser, R.; von Wolfersdorf, J. A comparison between transient heat transfer measurements using TLC and IR thermography. OPUS 2017. [CrossRef]

41. Brack, S.; Poser, R.; von Wolfersdorf, J. An approach to consider lateral heat conduction effects in the evaluation process of transient heat transfer measurements using TLC. Int. J. Therm. Sci. 2016, 107, 289-302. [CrossRef]

42. Ahmed, S.; Singh, P.; Ekkad, S.V. Three-Dimensional Transient Heat Conduction Equation Solution for Accurate Determination of Heat Transfer Coefficient. J. Heat Transf. 2020, 142, 051302. [CrossRef]

43. Ryley, J.R.; McGilvray, M.; Gillespie, D. Heat Transfer Coefficient Determination on 3D Geometries from Transient Thermochromic Liquid Crystal Experiments. J. Thermophys. Heat Transf. 2019, 33, 1132-1141. [CrossRef]

44. Jiang, H.; Chen, W.; Zhang, Q.; He, L. Analytical-Solution Based Corner Correction for Transient Thermal Measurement. J. Heat Transf. 2015, 137, 111302. [CrossRef]

45. Bergman, T.L.; Incropera, F.P.; DeWitt, D.P.; Lavine, A.S. Fundamentals of Heat and Mass Transfer; John Wiley \& Sons: Hoboken, NJ, USA, 2011.

46. Chyu, M.K.; Ding, H.; Downs, J.P.; Soechting, F.O. Determination of local heat transfer coefficient based on bulk mean temperature using a transient liquid crystals technique. Exp. Therm. Fluid Sci. 1998, 18, 142-149. [CrossRef] 
47. Jenkins, S.C.; Shevchuk, I.V.; von Wolfersdorf, J.; Weigand, B. Transient Thermal Field Measurements in a High Aspect Ratio Channel Related to Transient Thermochromic Liquid Crystal Experiments. J. Turbomach. 2011, 134, 031002. [CrossRef]

48. Singh, P.; Li, W.; Ekkad, S.V.; Ren, J. Experimental and numerical investigation of heat transfer inside two-pass rib roughened duct ( $\mathrm{AR}=1: 2)$ under rotating and stationary conditions. Int. J. Heat Mass Transf. 2017, 113, 384-398. [CrossRef]

49. Singh, P.; Li, W.; Ekkad, S.V.; Ren, J. A new cooling design for rib roughened two-pass channel having positive effects of rotation on heat transfer enhancement on both pressure and suction side internal walls of a gas turbine blade. Int. J. Heat Mass Transf. 2017, 115, 6-20. [CrossRef]

50. Singh, P.; Ji, Y.; Ekkad, S.V. Experimental and numerical investigation of heat and fluid flow in a square duct featuring criss-cross rib patterns. Appl. Therm. Eng. 2018, 128, 415-425. [CrossRef]

51. Ravi, B.V.; Singh, P.; Ekkad, S.V. Numerical investigation of turbulent flow and heat transfer in two-pass ribbed channels. Int. J. Therm. Sci. 2017, 112, 31-43. [CrossRef]

52. Singh, P.; Ravi, B.V.; Ekkad, S.V. Experimental and numerical study of heat transfer due to developing flow in a two-pass rib roughened square duct. Int. J. Heat Mass Transf. 2016, 102, 1245-1256. [CrossRef]

53. Axtmann, M.; von Wolfersdorf, J.; Meyer, G. Application of the Transient Heat Transfer Measurement Technique in a Low Aspect Ratio Pin Fin Cooling Channel. J. Turbomach. 2015, 137, 121006. [CrossRef]

54. Zhang, M.; Singh, P.; Ekkad, S.V. Rib Turbulator Heat Transfer Enhancements at Very High Reynolds Numbers. J. Therm. Sci. Eng. Appl. 2019, 11, 061014. [CrossRef]

55. Liu, J.; Hussain, S.; Wang, W.; Xie, G.; Sundén, B. Experimental and numerical investigations of heat transfer and fluid flow in a rectangular channel with perforated ribs. Int. Commun. Heat Mass Transf. 2021, 121, 105083. [CrossRef]

56. Singh, P.; Pandit, J.; Ekkad, S.V. Characterization of heat transfer enhancement and frictional losses in a two-pass square duct featuring unique combinations of rib turbulators and cylindrical dimples. Int. J. Heat Mass Transf. 2017, 106, 629-647. [CrossRef]

57. Madhavan, S.; Ramakrishnan, K.R.; Singh, P.; Ekkad, S. Jet Impingement Heat Transfer Enhancement by U-Shaped Crossflow Diverters. J. Therm. Sci. Eng. Appl. 2019, 12, 1-15. [CrossRef]

58. Singh, P.; Ji, Y.; Ekkad, S.V. Multipass Serpentine Cooling Designs for Negating Coriolis Force Effect on Heat Transfer: 45-deg Angled Rib Turbulated Channels. J. Turbomach. 2019, 141, 071003. [CrossRef]

59. Effect of Inclined Ribs on Heat Transfer Coefficient in Stationary Square Channel-ScienceDirect. Available online: https: / / www.sciencedirect.com/science/article/pii/S2095034917301307 (accessed on 30 August 2021).

60. Sharma, N.; Tariq, A.; Mishra, M. Detailed heat transfer and fluid flow investigation in a rectangular duct with truncated prismatic ribs. Exp. Therm. Fluid Sci. 2018, 96, 383-396. [CrossRef]

61. Experimental and Numerical Investigation of Turbulent Flow Heat Transfer in a Serpentine Channel with Multiple Short Ribbed Passes and Turning Vanes-ScienceDirect. Available online: https://www.sciencedirect.com/science/article/pii/S1290072921000 971 (accessed on 30 August 2021).

62. Rao, Y.; Guo, Z.; Wang, D. Experimental and Numerical Study of Heat Transfer and Turbulent Flow Characteristics in ThreeShort-Pass Serpentine Cooling Channels with Miniature W-Ribs. J. Heat Transf. 2020, 142, 121901. [CrossRef]

63. Liou, T.-M.; Chen, C.-C.; Wang, C.-S.; Wang, E.-S. Thermal-fluidic correlations for turbulent flow in a serpentine heat exchanger with novel wing-shaped turbulators. Int. J. Heat Mass Transf. 2020, 160, 120220. [CrossRef]

64. Promvonge, P.; Eiamsa-ard, S.; Wongcharee, K.; Chuwattanakul, V.; Samruaisin, P.; Chokphoemphun, S.; Nanan, K.; Eiamsa-ard, P. Characterization of heat transfer and artificial neural networks prediction on overall performance index of a channel installed with arc-shaped baffle turbulators. Case Stud. Therm. Eng. 2021, 26, 101067. [CrossRef]

65. Eiamsa-ard, S.; Chuwattanakul, V. Visualization of heat transfer characteristics using thermochromic liquid crystal temperature measurements in channels with inclined and transverse twisted-baffles. Int. J. Therm. Sci. 2020, 153, 106358. [CrossRef]

66. Shiau, C.-C.; Chen, A.F.; Han, J.-C.; Krewinkel, R. Detailed Heat Transfer Coefficient Measurements on a Scaled Realistic Turbine Blade Internal Cooling System. J. Therm. Sci. Eng. Appl. 2019, 12, 031015. [CrossRef]

67. Ekkad, S.V.; Singh, P. Detailed Heat Transfer Measurements for Rotating Turbulent Flows in Gas Turbine Systems. Energies 2021, 14, 39. [CrossRef]

68. Ekkad, S.V.; Singh, P. A Modern Review on Jet Impingement Heat Transfer Methods. J. Heat Transf. 2021, 143, 064001. [CrossRef]

69. Chen, L.; Brakmann, R.G.A.; Weigand, B.; Crawford, M.; Poser, R. Detailed heat transfer investigation of an impingement jet array with large jet-to-jet distance. Int. J. Therm. Sci. 2019, 146, 106058. [CrossRef]

70. Chen, L.; Brakmann, R.G.A.; Weigand, B.; Poser, R.; Yang, Q. Detailed investigation of staggered jet impingement array cooling performance with cubic micro pin fin roughened target plate. Appl. Therm. Eng. 2020, 171, 115095. [CrossRef]

71. Chen, L.; Brakmann, R.G.; Weigand, B.; Poser, R. An experimental heat transfer investigation of an impingement jet array with turbulators on both target plate and impingement plate. Appl. Therm. Eng. 2020, 166, 114661. [CrossRef]

72. Brakmann, R.; Chen, L.; Poser, R.; Rodriguez, J.; Crawford, M.; Weigand, B. Heat transfer investigation of an array of jets impinging on a target plate with detached ribs. Int. J. Heat Fluid Flow 2019, 78, 108420. [CrossRef]

73. Singh, P.; Zhang, M.; Ahmed, S.; Ramakrishnan, K.R.; Ekkad, S. Effect of micro-roughness shapes on jet impingement heat transfer and fin-effectiveness. Int. J. Heat Mass Transf. 2019, 132, 80-95. [CrossRef]

74. Rao, Y.; Liu, Y.; Wan, C. Multiple-jet impingement heat transfer in double-wall cooling structures with pin fins and effusion holes. Int. J. Therm. Sci. 2018, 133, 106-119. [CrossRef] 
75. Wang, N.; Chen, A.F.; Zhang, M.; Han, J.-C. Turbine Blade Leading Edge Cooling with One Row of Normal or Tangential Impinging Jets. J. Heat Transf. 2018, 140, 062201. [CrossRef]

76. Galeana, D.; Beyene, A. Gas Turbine Blade Heat Transfer and Internal Swirl Cooling Flow Experimental Study Using Liquid Crystals and Three-Dimensional Stereo-Particle Imaging Velocimetry. J. Energy Resour. Technol. 2021, 143, 102106. [CrossRef]

77. Pamula, G.; Ekkad, S.V.; Acharya, S. Influence of Crossflow-Induced Swirl and Impingement on Heat Transfer in a Two-Pass Channel Connected by Two Rows of Holes. J. Turbomach. 2000, 123, 281-287. [CrossRef]

78. Yang, L.; Singh, P.; Tyagi, K.; Pandit, J.; Ekkad, S.V.; Ren, J. Experimental Investigation of Rotational Effects on Heat Transfer Enhancement Due to Crossflow-Induced Swirl Using Transient Liquid Crystal Thermography. J. Therm. Sci. Eng. Appl. 2018, 10, 031001. [CrossRef]

79. Click, A.; Ligrani, P.; Ritchie, D.; Liberatore, F.; Patel, R.; Ho, Y.-H. Effects of coolant supply arrangement on double wall cooling: Hot-side effusion performance and cold-side Nusselt numbers at different initial blowing ratio. Int. J. Heat Mass Transf. 2020, 156, 119808. [CrossRef]

80. Ligrani, P.M. Vortex Structure Effects on Impingement, Effusion, and Cross Flow Cooling of a Double Wall Configuration. J. Phys. Conf. Ser. 2018, 980, 012018. [CrossRef]

81. Metzger, D.E.; Fan, C.S.; Haley, S.W. Effects of Pin Shape and Array Orientation on Heat Transfer and Pressure Loss in Pin Fin Arrays. J. Eng. Gas Turbines Power 1984, 106, 252-257. [CrossRef]

82. Dabagh, A.M.A.; Andrews, G.E. Pin-Fin Heat Transfer: Contribution of the Wall and the Pin to the Overall Heat Transfer. In Proceedings of the ASME 1992 International Gas Turbine and Aeroengine Congress and Exposition, Cologne, Germany, 1-4 June 1992. [CrossRef]

83. Goldstein, R.J.; Jabbari, M.Y.; Chen, S.B. Convective mass transfer and pressure loss characteristics of staggered short pin-fin arrays. Int. J. Heat Mass Transf. 1994, 37, 149-160. [CrossRef]

84. Baughn, J.W.; Ireland, P.T.; Jones, T.V.; Saniei, N. A Comparison of the Transient and Heated-Coating Methods for the Measurement of Local Heat Transfer Coefficients on a Pin Fin. J. Heat Transf. 1989, 111, 877-881. [CrossRef]

85. Hwang, J.-J.; Lui, C.-C. Detailed heat transfer characteristic comparison in straight and 90-deg turned trapezoidal ducts with pin-fin arrays. Int. J. Heat Mass Transf. 1999, 42, 4005-4016. [CrossRef]

86. Huang, S.-C.; Wang, C.-C.; Liu, Y.-H. Heat transfer measurement in a rotating cooling channel with staggered and inline pin-fin arrays using liquid crystal and stroboscopy. Int. J. Heat Mass Transf. 2017, 115, 364-376. [CrossRef]

87. Huang, S.-C.; Wang, C.-C.; Liu, Y.-H. Channel orientation effect on endwall heat transfer in rotating cooling passages with pin-fins. Int. J. Heat Mass Transf. 2019, 136, 1115-1126. [CrossRef]

88. Hung, S.-C.; Huang, S.-C.; Liu, Y.-H. Effect of nonuniform pin size on heat transfer in a rotating rectangular channel with pin-fin arrays. Appl. Therm. Eng. 2019, 163, 114393. [CrossRef]

89. Liang, C.; Rao, Y.; Luo, J.; Luo, X. Experimental and Numerical Study of Turbulent Flow and Heat Transfer in a Wedge-shaped Channel with Guiding Pin Fins for Turbine Blade Trailing Edge Cooling. Int. J. Heat Mass Transf. 2021, 178, 121590. [CrossRef]

90. Hussain, S.; Liu, J.; Wang, L.; Sundén, B. Suppression of endwall heat transfer in the junction region with a symmetric airfoil by a vortex generator pair. Int. J. Therm. Sci. 2019, 136, 135-147. [CrossRef]

91. Ratto, L.; Satta, F.; Tanda, G. An experimental and numerical study of endwall heat transfer in a turbine blade cascade including tangential heat conduction analysis. Heat Mass Transf. 2018, 54, 1627-1636. [CrossRef]

92. Liu, J.; Hussain, S.; Wang, W.; Wang, L.; Xie, G.; Sundén, B. Effect of the relative location of a pocket cavity on heat transfer and flow structures of the downstream endwall with a symmetrical vane. Int. J. Therm. Sci. 2019, 145, 106012. [CrossRef]

93. Liu, J.; Hussain, S.; Wang, L.; Xie, G.; Sundén, B. Effects of a pocket cavity on heat transfer and flow characteristics of the endwall with a bluff body in a gas turbine engine. Appl. Therm. Eng. 2018, 143, 935-946. [CrossRef]

94. Tamunobere, O.; Acharya, S. Turbine Shroud Heat Transfer and Cooling with Blade Rotation: Part I—Forward, Backward and Lateral Injection. In Proceedings of the ASME Turbo Expo 2017: Turbomachinery Technical Conference and Exposition, Charlotte, NC, USA, 26-30 June 2017. [CrossRef]

95. Liu, D.; Tao, Z.; Luo, X. Experimental investigation of heat transfer characteristics on turbine endwall with full coverage film cooling. Appl. Therm. Eng. 2018, 140, 295-303. [CrossRef]

96. Hayes, S.A.; Nix, A.C.; Nestor, C.M.; Billups, D.T.; Haught, S.M. Experimental investigation of the influence of freestream turbulence on an anti-vortex film cooling hole. Exp. Therm. Fluid Sci. 2017, 81, 314-326. [CrossRef]

97. Dhungel, A.; Lu, Y.; Phillips, W.; Ekkad, S.V.; Heidmann, J. Film Cooling From a Row of Holes Supplemented with Antivortex Holes. J. Turbomach. 2009, 131, 021007. [CrossRef]

98. Ye, L.; Liu, C.; Liu, F.; Yang, Y.; Zhu, H. Experimental Study on Heat Transfer of Leading Edge Film-Cooling with Counter-Inclined Cylindrical and Laid-Back Holes. J. Heat Transf. 2020, 142, 061801. [CrossRef]

99. Liu, C.; Ye, L.; Zhang, F.; Huang, R.; Li, B. Film cooling performance evaluation of the furcate hole with cross-flow coolant injection: A comparative study. Int. J. Heat Mass Transf. 2021, 164, 120457. [CrossRef]

100. Zhang, B.; Zhu, H.; Liu, C.; Wei, J. Experimental Study on the Film-Cooling Characteristics of the Cylindrical Holes Embedded in Sine-Wave Shaped Trench. J. Eng. Gas Turbines Power 2020, 142, 101003. [CrossRef] 